\title{
Co-administration of hydroalcoholic Viola odorata's extract and streptozotocin on histopathological and biochemical changes in rat kidney
}

\author{
Rouhollah Gazor ${ }^{1}$, \\ Atieh Ashouri2, \\ Monireh Aghajany-nasab ${ }^{3}$, \\ Fatemeh Yousefbeyk ${ }^{4}$, \\ Behrooz Khakpour Taleghani5, \\ Fahimeh Mohammadghasemi ${ }^{1^{*}}$ \\ 1 Cellular \& Molecular Research Center, \\ Department of Anatomy, School of \\ Medicine, Guilan University of Medical \\ Sciences, Rasht-Iran \\ 2 Student Research Center, Department of \\ Anatomy, School of Medicine, Guilan \\ University of Medical Sciences, Rasht- \\ Iran \\ 3 Cellular \& Molecular Research Center, \\ Department of Biochemistry, School of \\ Medicine, Guilan University of Medical \\ Sciences, Rasht-Iran \\ ${ }^{4}$ Department of Pharmacognosy, School \\ of Pharmacy, Guilan University of \\ Medical Sciences, Rasht-Iran \\ 5 Department of Physiology, School of \\ Medicine, Guilan University of Medical \\ Sciences, Rasht-Iran
}

\section{*Corresponding author:}

Fahimeh Mohammadghasemi

ghasemi_fm@gums.ac.ir,

parsahistolab@gmail.com

\begin{abstract}
This study aimed to evaluate the effect of hydroalcoholic Viola odorata extract (VOE) on kidney tissue in a diabetic rat model induced by streptozotocin (STZ). Male Wistar rats were randomly divided into five groups: 1. Vehicle controls, 2. STZ, 3. STZ+ 100 $\mathrm{mg} / \mathrm{kg}$ (VOE), 4 . STZ+ 200mg/kg (VOE) 5 . STZ+ $400 \mathrm{mg} / \mathrm{kg}$ (VOE). At the end of the experiment serum and urinary levels of urea, creatinine, albumin, serum glucose, and MDA levels were measured. Tuft glomerular and renal corpuscles area, epithelial height in proximal and distal convoluted tubules (PCT and DCT) were quantitatively measured in histologic slides. VOE in doses of 100, 200, and 400 $\mathrm{mg} / \mathrm{kg}$ significantly reduced the serum glucose level. VOE in dose of $200 \mathrm{mg} / \mathrm{kg}$ reduced urine albumin, creatinine, and urea in comparison with STZ treated group $(P<0.001)$. VOE in a dose of $400 \mathrm{mg} / \mathrm{kg}$ also reduced urine albumin $(P<0.01)$. There were no significant statistical differences in serums' kidney markers between the STZ and VOE groups. $100 \mathrm{mg} / \mathrm{kg}$ and $200 \mathrm{mg} / \mathrm{kg}$ of VOE reduced serum MDAlevel compared to the STZ group. Treatment with various doses of VOE effectively reduced both the tuft glomerular and renal corpuscles area. Epithelial height in PCT and DCT reduced in STZ treated group compared to controls. $200 \mathrm{mg} / \mathrm{kg}$ VOE increased them significantly $(P<0.001)$. The results showed that VOE has hypoglycemic properties. VOE may protect renal function induced by STZ, especially in a dose of $200 \mathrm{mg} / \mathrm{kg}$ and through reduction of oxidative stress.
\end{abstract}

\section{INTRODUCTION}

Diabetes is a metabolic disorder of the endocrine system ${ }^{1}$. Keywords:

Viola, Diabetes, Kidney, Oxidative stress
Pharmaceutical Sciences Asia $\odot 2021$ by Faculty of Pharmacy, Mahidol University, Thailand is licensed under CCBY-NC-ND 4.0. To view a copy of this license, visit https:// www.creativecommons.org/ licenses/by-nc-nd/4.0/
Mellitus (DM) is one of the five leading causes of death in the world ${ }^{2}$. The global prevalence of diabetes has been dramatic over the past 10 years $^{3}$. The important causes of this disease are family history, poor dietary patterns, obesity, a high caloric diet, and sedentary behavior. Hyperglycemia leads to various organs dysfunction, such as kidneys, liver, heart, reproductive system and blood vessels ${ }^{3}$. Kidney function is impaired in DM that is characterized by proteinuria and loss of renal function. In the end-stage of DM hypertension is occurred. Histologically DM changes kidney structure including glomerular basement membrane, mesangial expansion, and also glomerulusclerosis $^{4}$. There is evidence that shows antioxidant enzymes are impaired in diabetes mellitus ${ }^{5}$. Therefore, it suggests oxidative stress has an important role in the development of $\mathrm{DM}^{6}$. Previous 
studies in diabetic patients and diabetic animals have shown that free radicals, membrane lipid peroxidation, and protein oxidation are increased. Insulin and hypoglycemic agents are the main effective treatment for DM. Hypoglycemia, weight gain, headache, and elevating liver enzymes are the side effects of these agents ${ }^{5}$.

The WHO has also recommended the use of herbal anti glycemic agents in traditional medicine ${ }^{7}$. Side effects of herbal drugs and plants are fewer in compare with chemical drugs. Researchers are looking for new herbal compounds for the treatment or preventing the disease ${ }^{8}$. Applicants for new herbal medicine are on the rise today. They hope that this new herbal medicine will reduce the side effects of chemical and synthetic drugs.

Viola odorata (V.odorata) is commonly known as sweet violet and is native to Europe and Asia, as well as in North America and Australia9. Different types of violets are used to improve liver and kidney function ${ }^{10}$. Studies have shown that some species of this plant are rich in antioxidants because of phenolic compounds ${ }^{11}$.

This study aimed to investigate the effect of $V$. odorata on kidney structural changes, some renal function and serum oxidant status in diabetic rats.

\section{MATERIALS AND METHODS}

\subsection{Preparation of extract}

The flowers of V.odorata were collected from Ramsar, Mazandaran province in North of Iran, in May, 2017. The plant was identified and given herbarium specimen number (HGUM-302). The voucher specimen was deposited in herbarium of school of pharmacy, Guilan University of Medical Sciences, Rasht, Iran. The flowers $(500 \mathrm{~g})$ were shade dried and crushed to a powder and then extracted by percolation with ethanol (70\%), at room temperature for one week. The solvent was evaporated by rotary evaporator and stored in a refrigerator until required ${ }^{11}$.

\subsection{Animals and induction of diabetes:}

In this study, 40 adult Wistar male rats $(250 \pm 10 \mathrm{~g})$ were used. Animals were randomly divided into five experimental groups. The rats were maintained under standard conditions with a 12-h light and 12-h dark cycle at room temperature $\left(23^{\circ} \mathrm{C}\right)$. They had access to food and tap water ad libitum. This study was done by following the guidelines provided by the Animal Laboratory. All principles of animal work were carried out according to the ethics committee approved by Guilan University of Medical Sciences (animal protocol number: IR.GUMS.REC.1395.226).

Control group received normal saline, STZ group: received STZ45 mg/kg, STZ groups were divided into three subgroups and treated with 100,200 , and $400 \mathrm{mg} / \mathrm{kg} \mathrm{V}$. odorata extract (VOE).

In this study to induce diabetes, a single dose of STZ $(45 \mathrm{mg} / \mathrm{kg})$ was used intraperitoneally. STZ solution prepared freshly and injected. After three days, blood glucose (BG) was measured. Animals with BG levels $>250 \mathrm{mg} / \mathrm{dl}$ were considered as diabetic ${ }^{12-13}$.

Administration of VOE started 3 days after induction of diabetes by the injection of STZ. VOE were administered intraperitoneally once a day, for 30 days. At the end of the experiment, animals were weighted and urine samples were obtained for the study of renal function. Fresh urine collected with a mild intervention as previously is described by Khosho et al in $1985^{14}$. Each mouse was placed in a cool glass finger bowl (diameter $16 \mathrm{~cm}$ ) to stimulate urination. Urine samples were collected twice, 8-9 am and 13-14 pm in each mouse. Then both urine samples were pooled for analysis ${ }^{15}$. For collecting more urine sample the back of the animal was tickled using the fingers and also a cold pad was put below the animal's abdomen for about 30 seconds. Then using a Pasteur pipet urine collected in a $2 \mathrm{ml}$ vial and stored at $20^{\circ} \mathrm{c}$ until analysis. All surgery was performed under anesthesia and every effort was made to minimize suffering. Animals were anesthetized intraperitoneally with $50 \mathrm{mg} / \mathrm{kg}$ ketamine and $22 \mathrm{mg} / \mathrm{kg}$ xylazine. The right kidney was removed for histologic study. A Blood sample obtained from inferior vena cava.

\subsection{Biochemical assay}

Blood samples were centrifuged at 4000 rpm for $10 \mathrm{~min}$. Then serum separated and stored at $-20^{\circ} \mathrm{C}$. FBG levels were measured using (Parse Azmun -Iran) kit. Serum and urinary, creatinine albumin and urea levels were measured by the kits were tested using a photometric method.

\subsection{Malondialdehyde (MDA) Assay}

Content of MDA assayed in serum using ELISA kit (Bioassay, China). The basis of the assay was redox colorimetric. After reaction optical absorption read at $450 \mathrm{~nm}$ wavelength. 
The sensitivity of the kit was $0.14 \mathrm{nmol} / \mathrm{ml}$ and the diagnostic range was $0.2-60 \mathrm{nmol} / \mathrm{ml}$.

\subsection{Histologic study}

All kidney tissues were fixed in $10 \%$ neutral buffered formalin for $72 \mathrm{~h}$. Then the tissue passage was carried out with alcohol with graded doses of $50,70,90,100 \%$ for dehydration, and xylene for infiltration, and paraffin for molding. Using a rotary microtome (Leitz - Germany), 5micron sections were prepared. All observations were made by an optical microscope (Olympus Japan) with 400x. At least 15 renal corpuscles/ animal and 15 tubules (proximal and distal)/animal evaluated quantitatively. Measurements, such as the area of the glomerular tuft and renal corpuscles, the epithelial height of the proximal convoluted tubule (PCT) and distal convoluted tubules (DCT) were studied. To evaluate the histomorphometry, the software Digimizer Version 11 was used and data were expressed as micrometer $(\mu \mathrm{m})$ and square micrometer $\left(\mu \mathrm{m}^{2}\right)$.

\subsection{Data analysis methods:}

The distribution of data for normalization was studied using the K-S method. To compare the groups, the ANOVA method was used and if there was a significant difference between the groups, the Tuckey test was used. The results of each group were calculated and reported as mean and standard error (Mean \pm SE). The value of $P<0.05$ was considered a significant difference.

\section{RESULTS}

\subsection{Biochemical results}

Biochemical results showed that alcohollic extract in 100, 200 and $400 \mathrm{mg} / \mathrm{kg}$ of VOE reduced serum glucose levels compared to the STZ group (Figure 1). Serum albumin and urea in the STZ group significantly were higher than the controls. There was not significant statistical differences in serum albumin, creatinine and urea between VOE treated groups and STZ group. (Figure 1).

Urinary analysis showed that a dose of $100 \mathrm{mg} / \mathrm{kg}$ VOE was not effective on urinary markers. However, the group receiving a dose of $200 \mathrm{mg} / \mathrm{kg}$ VOE all urinary parameters such as albumin, urea, and creatinine reduced compared with the STZ group $(P<0.05)$. Meanwhile, $400 \mathrm{mg} / \mathrm{kg}$ dose of VOE reduced the level of urine albumin in comparison with the STZ group $(P<0.001)$

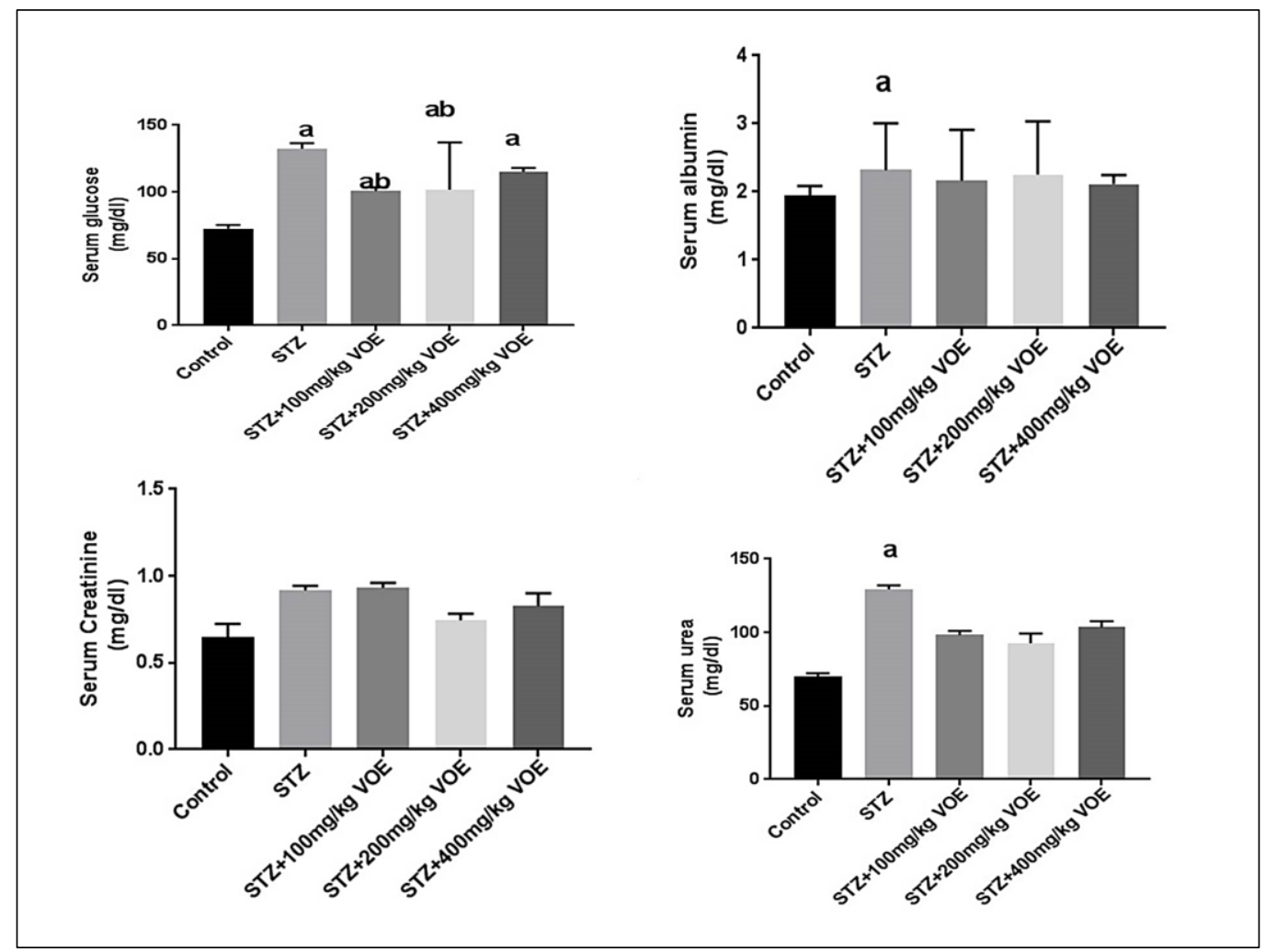

Figure 1. The effect of VOE on serum biochemistry parameters of male diabetic rats.

Values are expressed in mean \pm S.E. a: significant values compared to the control group, $p<0.001$ and b: significant values compared to the STZ treated group. $p<0.05$. 


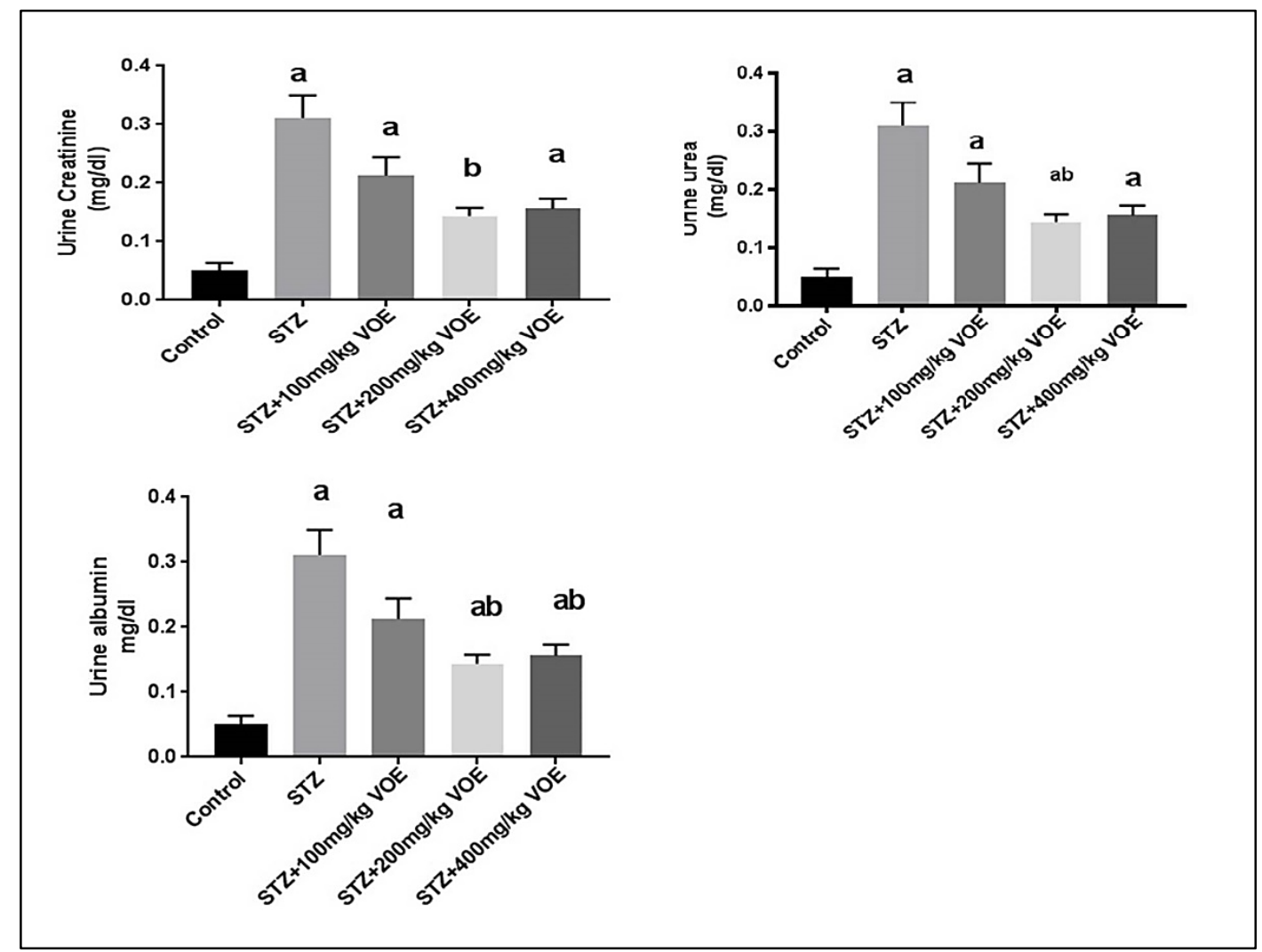

Figure 2. The effect of VOE on urinary biochemistry parameters of male diabetic rats.

Values are expressed in mean \pm S.E. a: significant values compared to the control group, $p<0.001$ and b: significant values compared to the STZ treated group. $p<0.01$.

(Figure 2). Creatinine level in doses of $100 \mathrm{mg} / \mathrm{kg}$ and $400 \mathrm{mg} / \mathrm{kg}$ VOE reduced insignificantly compared with the STZ group (Figure 2).

\subsection{Malondialdehyde (MDA) Assay}

Serum MDA level in the STZ group increased about 3 folds in compare with controls $(p<0.001)$. Treatment with $100 \mathrm{mg} / \mathrm{kg}$ and 200 $\mathrm{mg} / \mathrm{kg}$ VOE significantly reduced serum MDA level compared with STZ treated group. VOE in a dose of $400 \mathrm{mg} / \mathrm{kg}$ reduced MDA level, however, it was not significant (Figure 3).

\subsection{Histologic results}

Histologic study showed renal corpuscles expanded and the area of both tuft glomerular and renal corpuscles in the STZ group significantly increased compared to controls $(p<0.001)$. Bowman space observed larger in the STZ group. The colony of inflammatory cells in the interstitial tissue and around blood vessels observed in the STZ group. Epithelial height of PCT and DCT reduced in STZ treated group compared to controls (Figure 4). The abnormalities were restored by treatment with VOA especially in the dose of
(200 mg/kg). Thus, the VOE extract might repair the damaged kidney morphology caused by diabetes (Figure 4 and Table 1).

\section{DISCUSSION}

The present study showed the administration of STZ caused diabetes in animals. In this study, we used VOE in doses of $100 \mathrm{mg} / \mathrm{kg}$, $200 \mathrm{mg} / \mathrm{kg}$ and $400 \mathrm{mg} / \mathrm{kg}$ to determine its antidiabetic and renoprotective effects. Also, 200 $\mathrm{mg} / \mathrm{kg}$ VOE reduced the urinary amount of albumin, urea, and creatinine compared to the STZ group. STZ increased the area of both glomerular tuft and renal corpuscles but VOE in different doses reduced them. Medicinal plants have used for the treatment of diabetes since 1550 B.C. Various herbs, spices, and plant materials have been used for this purpose throughout the world ${ }^{13}$. A decrease in serum albumin, urea and creatinine levels following some doses of VOE may be due to inhibition of oxidative phosphorylation process, which resulted in a reduction of protein absorption, protein synthesis, and an elevation in the catabolic process ${ }^{16}$. Maybe an elevation of glucose concentration in serum or tissues resulted in the elevation of ROS formation 


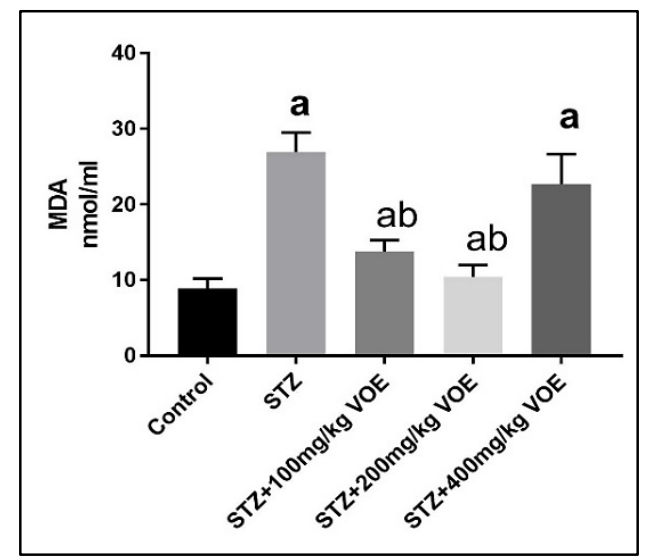

Figure 3. Serum MDA levels in groups. a: significant data compared with controls $p<0.001$, b: significant data compared with the STZ treated group $p<0.001$. Data are presented in mean \pm S.E.

Table 1. The effect of the VOE on the morphometric parameters of kidney tissue in diabetic male rats.

\begin{tabular}{lccccc}
\hline Groups & Control & STZ & STZ+100 $\mathbf{~ m g / k g ~ V O E ~}$ & STZ+200 $\mathbf{~ m g / k g ~ V O E ~}$ & STZ+400 $\mathbf{~ m g / k g ~ V O E ~}$ \\
\hline $\begin{array}{l}\text { Glomerular tuft } \\
\text { area }\left(\mu \mathrm{m}^{2}\right)\end{array}$ & $5572 \pm 610$ & $14440 \pm 02^{\mathrm{a}}$ & $9724 \pm 410^{\mathrm{b}}$ & $7438 \pm 341^{\mathrm{b}}$ & $8971 \pm 431$ \\
$\begin{array}{l}\text { Renal corpuscle } \\
\text { area }\left(\mu \mathrm{m}^{2}\right)\end{array}$ & $8918 \pm 419$ & $22283 \pm 70^{\mathrm{a}}$ & $12321 \pm 640^{\mathrm{b}}$ & $10456 \pm 651^{\mathrm{b}}$ & $12368 \pm 410^{\mathrm{b}}$ \\
$\begin{array}{l}\text { DCT epithelial } \\
\text { height }(\mu \mathrm{m})\end{array}$ & $9.28 \pm 1.6$ & $5.74 \pm 0.9^{\mathrm{a}}$ & $8.34 \pm 1.5^{\mathrm{b}}$ & $8.78 \pm 1.7^{\mathrm{b}}$ & $7.38 \pm 1.5$ \\
$\begin{array}{l}\text { PCT epithelial } \\
\text { height }(\mu \mathrm{m})\end{array}$ & 17.78 & 10.38 & $13.24^{\mathrm{b}}$ & $13.65^{\mathrm{b}}$ & 12.52 \\
\hline
\end{tabular}

Values are expressed in mean \pm S.E. a: Significant values compared to the control group, $p<0.001$, b: significant values compared to the STZ treated group. $p<0.05$. PCT: proximal convoluted tubules. DCT: Distal convoluted tubules

and therefore it may have a role in the pathology of diabetes nephropathy ${ }^{17}$.

Oxidative stress is one of the most important causes of diabetes. Diabetes trough some mechanisms such as hyperglycemia, hyperlipidemia, and hypertension induces oxidative stress ${ }^{18}$. Therefore, it seems antioxidant therapy may protect or prevent diabetes complications. Our study confirmed that VOE reduced serum MDA levels as a marker of oxidative stress in comparison with the STZ group. In this regard, it has been shown that the water extract of VOE has free radical scavenging activity ${ }^{19}$. Similarly, Benafsha Atri (a kind of Viola), reduces the level of serum glucose which is in confirmation with our study. A previous study has been shown that the viola contains anthocyanin ${ }^{20}$. Anthocyanins have anti-bacterial, antihistamine, anti-allergic, anti-malarial, lipid, cholesterol, and anti-diabetic effects ${ }^{21}$. Also, the presence of liver protective flavonoids has been proven in this plant ${ }^{21}$. Similarly, phytochemicals of berries have potential health activities against $\mathrm{T}_{2} \mathrm{DM}^{6}$.

Researches have shown VOE contains a combination of alkaloids, glycosides, tannins, steroids, triploids, saponins, flavonoids, methyl salicylates, mucilages and vitamins $\mathrm{C}^{19-22}$. About 30 cyclotides are known in both root and air organs of the $V$. odorata plant ${ }^{23}$. The root of this plant contains a violin alkaloid that is used as an expectorant ${ }^{9}$. Various reports have shown that the anti-diabetic properties of medicinal plants are due to the presence of saponin. The ability of saponin to reduce plasma glucose levels has made saponins an excellent candidate for diabetes mellitus ${ }^{24}$. So far, flavonoid glycosides, mainly derivatives of kaempferol, quercetin and apigenin have been reported from V.odorata ${ }^{20}$. Flavonoids through improvement of lipid profile, antioxidants level, and glycemic level have therapeutic effects on diabetes. Among them, rutin, as a flavonoid which is reported in V.odorata, indicated significant biological properties like antioxidant, nephronprotective, neuroprtective and anti-inflammatory ${ }^{25}$.

Previous studies have shown the effects of perfume violet powder on liver and kidney function following tetrachloride (CCL4) liver toxicity ${ }^{10}$. The exact mechanisms of the effect of VOE on renal tissue is unknown and needs more investigations.

\section{CONCLUSIONS}

In conclusion, the results of the present study showed that VOE has hypoglycemic properties VOE may protect renal function induced by STZ, especially in a dose of $200 \mathrm{mg} / \mathrm{kg}$ and 

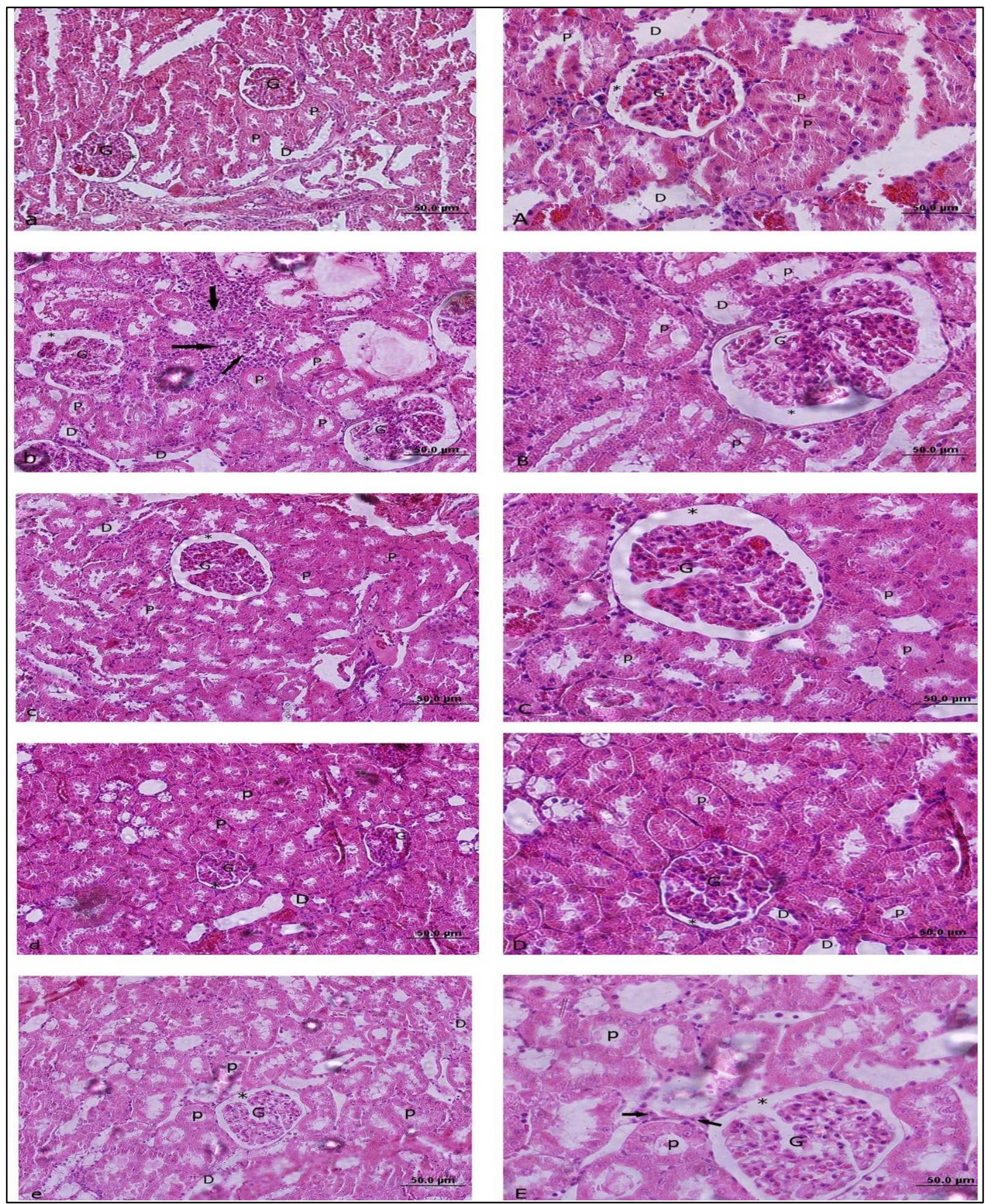

Figure 4. Photomicrograph of the rat kidney tissue. a and A: Control group, b, and B: STZ group, c, and C: STZ+ $100 \mathrm{mg} / \mathrm{kg}$ VOE group, d and D: STZ + $200 \mathrm{mg} / \mathrm{kg}$ VOE, e and E: STZ + $400 \mathrm{mg} / \mathrm{kg}$ VOE. G: Glomerulus tuft, P: proximal convoluted tubule, D: distal convoluted tubule, * shows bowman space, arrows represent the aggregation of inflammatory cells. In figure b and B: STZ treated group please note to an expansion of renal glomerulus tuft, renal corpuscles, and Bowman's space. Also, note to a reduction of epithelial height in proximal and distal convoluted tubules. Note that STZ+100mg/kg VOE and STZ+200mg/kg VOE have restored most of the abovementioned structural abnormalities in the kidney. H\&E staining. $200 \times$ and $400 \times$. 
through reduction of oxidative stress.

\section{ACNOWLEDGEMENT}

We are grateful to Mr Hamid Morovati for help to the animal care and handling.

\section{Funding}

This study is supported financially by the Deputy of Research and Technology of the Guilan University of Medical Sciences (95071709).

\section{Conflict of interest}

The results of this article are not in conflict with the interests of the authors.

\section{Ethical approval}

This study was done by following the guidelines provided by the Animal Laboratory. All principles of animal work were carried out according to the ethics committee approved by Guilan University of Medical Sciences (animal protocol number: IR.GUMS.REC.1395.226).

\section{Article info:}

Received April 20, 2020

Received in revised form June 30, 2020

Accepted October 10, 2020

\section{REFERENCES}

1. Li W, Zheng H, Bukuru J, De Kimpe N. Natural medicines used in the traditional Chinese medical system for therapy of diabetes mellitus. J Ethnopharmacol. 2004;92(1):1-21.

2. Joseph B, Jini D. Antidiabetic effects of Momordica charantia (bitter melon) and its medicinal potency. Asian Pac J Trop Dis. 2013;3(2):93-102.

3. Erkelens DW. Insulin resistance syndrome and type 2 diabetes mellitus. Am J Cardiol. 2001;88(7):38-42.

4. Azizi F, Madjid M, Rahmani M, Emami H, Mirmiran P, Hadjipour R. Tehran Lipid and Glucose Study (TLGS): rationale and design. Iran J Endocrinol Metab 2000; 2(2):77-86.

5. Kalra S, Mukherjee JJ, Venkataraman S, Bantwal G, Shaikh S, Saboo B, et al. Hypoglycemia: The neglected complication. Indian JEndocrinol Metab. 2013;17(5):819.

6. Svarcovaa I, Heinrichb J, Valentovaa K. Berry fruits as a source of biologically active compounds: the case of Lonicera caerulea. Biomed Pap Med Fac Univ Palacky Olomouc Czech Repub. 2007;151(2):163-74.

7. Lu HE, Jian C H, Chen S F, Chen TM, Lee S T, Chang C $\mathrm{S}$, et al. Hypoglycaemic effects of fermented mycelium of Paecilomyces farinosus (G30801) on high-fat fed rats with streptozotocin-induced diabetes. Indian J Med Res. 2010;131(5):696.

8. Isah A, Ibrahim Y, Abdulrahman E, Ibrahim M. The hypoglycaemic activity of the aqueous extract of Stachytarpheta angustifolia (Verbanaceae) in normog- lycaemic and alloxan-induced diabetic rats. Pak J Biol Sci. 2007;10(1):137-41.

9. Mittal P, Gupta V, Goswami M, Thakur N, Bansal P. Phytochemical and pharmacological potential of viola odorata. Int J Pharmacogn. 2015;4:693.

10. Elhassaneen Y, Sabry S, Musalum T, El-Eskafy A, ElFatah AA. Effect of sweet violet (Viola odorata L.) blossoms powder on liver and kidney functions as well as serum lipid peroxidation of rats treated with carbon tetrachloride. J Am Sci. 2013;9(5):88-95.

11. Muhammad N, Saeed M. Biological screening of Viola betonicifolia Smith whole plant. Afr J Pharm Pharmacol. 2011;5(20):2323-9.

12. Furman BL. Streptozotocin-induced diabetic models in mice and rats. Curr Protoc Pharmacol. 2015;70(1):5.47. 1-20.

13. Kesari AN, Gupta RK, Singh SK, Diwakar S, Watal G. Hypoglycemic and antihyperglycemic activity of Aegle marmelos seed extract in normal and diabetic rats. $\mathbf{J}$ Ethnopharmacol. 2006;107(3):374-9.

14. Khosho F, Kaufmann R, Amankwah K. A simple and efficient method for obtaining urine samples from rats. Lab Anim Sci. 1985;35(5):513-4.

15. Vasta JD, Fried B, and Sherma J, High-performance thin-layer chromatographic analysis of neutral lipids in the urine of humans and BALB/c mice. JPC-J Planar Chromat. 2008; 21(1): 39-42.

16. Prakasam A, Sethupathy S, Pugalendi KV. Influence of Casearia esculenta root extract on protein metabolism and marker enzymes in streptozotocin-induced diabetic rats. Pharmacol Rep. 2004;56(5):587-94.

17. Koya D, Hayashi K, Kitada M, Kashiwagi A, Kikkawa R, Haneda M. Effects of antioxidants in diabetes-induced oxidative stress in the glomeruli of diabetic rats. J Am Soc Nephrol. 2003;14(8suppl 3):S250-3.

18. Johansen JS, Harris AK, Rychly DJ, Ergul A. Oxidative stress and the use of antioxidants in diabetes: linking basic science to clinical practice. Cardiovasc Diabetol. 2005;4(1):5.

19. Stojković D, Glamočlija J, Ćirić A, Šiljegović J, Nikolić M, Soković M. Free radical scavenging activity of Viola odorata water extracts. J Herbs Spices Med Plants. 2011;17(3):285-90.

20. Karioti A, Furlan C, Vincieri FF, Bilia AR. Analysis of the constituents and quality control of Viola odorata aqueous preparations by HPLC-DAD and HPLC-ESIMS. Anal Bioanal Chem.2011;399(4):1715-23.

21. Qadir MI, Ali M, Saleem M, Hanif M. Hepatoprotective activity of aqueous methanolic extract of Viola odorata against paracetamol paracetamol-induced liver injury in mice. Bangladesh J Pharmacol. 2014;9(2).

22. Feyzabadi Z, Jafari F, Kamali SH, Ashayeri H, Aval SB, Esfahani MM, et al. Efficacy of Viola odorata in treatment of chronic insomnia. Iran Red Crescent Med J. 2014; 16(12)

23. Ireland DC, Colgrave ML, Craik DJ. A novel suite of cyclotides from $\mathrm{V}$. odorata: sequence variation and the implications for structure, function and stability. J Pept Sci. 2006;12(S1):143.

24. Elekofehinti OO. Saponins: Anti-diabetic principles from medicinal plants-A review. Pathophysiology. 2015;22(2):95-103.

25. Ghorbani A. Mechanisms of antidiabetic effects of flavonoid rutin. Biomed Pharmacother. 2017;96: 305-12. 